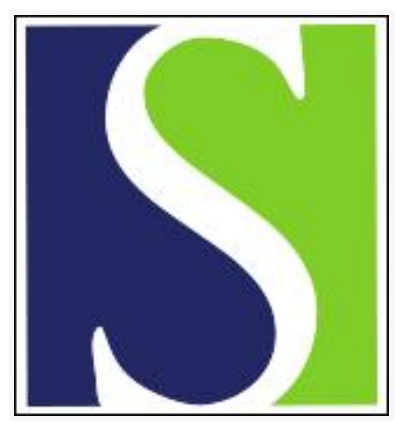

Scand J Work Environ Health 2006;32(5):349-358

https://doi.org/10.5271/sjweh.1030

Issue date: 31 Oct 2006

Impact of an 84-hour workweek on biomarkers for stress, metabolic processes and diurnal rhythm

by Persson R, Ørbæk P, Kecklund G, Åkerstedt T

Affiliation: National Institute of Occupational Health, Lersø Parkallé 105, 2100 København Ø, Denmark. rpe@ami.dk

Refers to the following texts of the Journal: 1997;23(4):257-265

2003;29(3):171-188 2005;31 suppl 2:22-26 2003;29(4):261-269

The following article refers to this text: 2016;42(1):26-33

Key terms: 84-hour workweek; biomarker; diurnal rhythm; diurnal type; health complaint; hormone; impact; metabolic process; serum; sleep; stress

This article in PubMed: www.ncbi.nlm.nih.gov/pubmed/17091202 


\title{
Impact of an 84-hour workweek on biomarkers for stress, metabolic processes and diurnal rhythm
}

\author{
by Roger Persson, PhD, ${ }^{1,2}$ Palle Ørbæk, MD, ${ }^{1,2}$ Göran Kecklund, PhD, ${ }^{3}$ Torbjörn Åkerstedt, PhD ${ }^{3}$
}

\begin{abstract}
Persson R, Ørbæk P, Kecklund G, Åkerstedt T. Impact of an 84-hour workweek on biomarkers for stress, metabolic processes and diurnal rhythm. Scand J Work Environ Health 2006;32(5):349-358.

Objectives This study examined the degree to which long workhours in combination with an extended workweek (12 hours/7 days) with permanent day shifts (0700-1900), as requested by the workers, influenced biomarkers for stress, metabolic processes, and diurnal rhythm.

Methods Construction workers $(\mathrm{N}=50)$ working 84 hours a week, with alternate weeks off, were compared with construction workers $(\mathrm{N}=25)$ having a traditional 40-hour work schedule. The participants were all male and between the ages of 21 to 65 years. Blood samples were obtained in the morning immediately prior to the start of work on workday 1,5 , and 7 to assess cholesterol, cortisol, dehydroepiandrosterone, melatonin, prolactin, testosterone, and uric acid. Psychosocial circumstances were assessed with a questionnaire.

Results The 84-hour group had higher melatonin concentrations and reported higher job-control scores than the 40-hour group. For both groups, the melatonin, cortisol, and cholesterol concentrations were lower on workday 5 than on workday 1 . In the 84-hour group, most of the biomarkers were significantly lower in concentrations on workday 7 than on workday 1 . Only testosterone showed a significant decrease between workdays 5 and 7. The concentrations of dehydroepiandrosterone and uric acid remained stable across all of the days, as did the melatonin concentrations between workdays 5 and 7.

Conclusions Working of one's own free will on an 84-hour regimen is not, in the short-term, necessarily more harmful for health than working on a 40-hour regimen with a similar type of heavy worktasks. However, working on an 84-hour schedule beyond the ordinary 40-hour week results in signs of a functional shift in hormonal regulation.
\end{abstract}

Key terms diurnal type; health complaint; hormone; serum; sleep.

While occupational health research has been successful in linking shift work allocated outside standard workhours (ie, between 1800-0600) with metabolic impact and pathological disorders, for example, peptic ulcer and coronary heart disease (1-3), research focusing on extended workshifts during standard workhours (ie, up 12 hours a day, between 0600-1800) has not revealed conclusive evidence of a negative impact on health (4). However, as shown in a recent review (5), there are many indications that long workhours independent of shift work, or as part of compressed workweeks, may be associated with adverse health for a range of physiological and psychological indicators such as cardiovascular disease, diabetes, and self-reported health and fa- tigue. A major reason for the inconclusive results may be that a variety of occupational settings and work schedules has been investigated-a fact likely to reflect the diversity of the labor market.

One industrial setting in which the impact of long workhours has received little attention is large-scale construction work, for example, bridge and tunnel construction (6). Yet, two Danish epidemiologic studies have shown that the incidences of disability retirement, and of diseases requiring hospital treatment (eg, infectious disease, diseases of the nervous system and ischemic heart disease) are higher among large-scale construction workers than among other construction workers $(7,8)$. Even if long workhours are often appreciated by certain

1 Department of Occupational and Environmental Medicine, Lund University Hospital, Lund, Sweden.

2 National Institute of Occupational Health, Copenhagen, Denmark.

3 National Institute for Psychosocial Medicine, Stockholm, Sweden.

Reprint requests to: Dr R Persson, National Institute of Occupational Health, Lersø Parkallé 105, 2100 København $\emptyset$, Denmark. [E-mail: rpe@ami.dk] 
groups of workers, which find the economic incentives and possibilities for extended leaves between workshifts attractive, there is reason to believe that the combination of large-scale construction work and long hours comprises strain that increases the risk of poorer health.

In the present case, the local labor inspectorate raised their concerns when an 84-hour workweek (ie, 12 hours per day for 7 days, with alternate weeks off) was introduced at the workers' request on a large bridge construction site in the southern most part of Sweden. The heavy work, and the marked difference from the ordinary 40hour workweek that encompasses 5 days of work and 2 days off, was suspected to lead to accumulated fatigue, and thus possibly compromised the workers' physical and mental status and jeopardized safety at work. The scheduling was, however, accepted provided medical supervision and evaluation took place. The medical supervision and evaluation involved a multitude of methods and effect markers, for example, questionnaires, hormones in blood and saliva, heart rate variability, muscle fatigue, objective sleep monitoring, and neurobehavioral tests. The accumulated effects of this 84-hour scheduling on cognitive performance have been addressed in a previous paper, in which we concluded that basic mental capabilities remained intact (9). In this paper, we present the results from the physiological monitoring and questionnaire data about health complaints, sleep, work situation, and social interactions. The primary objective was to examine whether working 84hours a week led to altered physiological regulation or imbalances between catabolic and anabolic processes with possible detrimental consequences for metabolism and circadian rhythm. Specifically, it was of interest to examine whether the development of these imbalances, or shifts in physiological regulation, during the workweek were manifested already at the start of work and hence not corrected back to basal levels by sleep or other activities after work. Although physiological reactivity by, for example, the excretion of hormones in the short run is thought to promote individual adaptation to various environmental challenges, physiological reactivity is also, if not turned off and returned to basal levels after adaptive efforts, thought to represent the first step in a chain of events that may lead to disease $(10,11)$. Basically, the pathophysiological mechanism is thought to be sustained arousal causing nonspecific wear and tear. The organ system (eg, cardiovascular or stomach) that is the primary target of the sustained arousal depends both on the external circumstances and on individual differences in susceptibility. Accordingly, it was hypothesized that the 84-hour group would show signs of increased activity in biological systems and that the increased activity would promote immediate energy expenditure while inhibiting the systems involved in restitution.

\section{Study population and methods}

\section{Study population and design}

Two groups of male construction workers were examined. The first group $(\mathrm{N}=50)$ worked repeating cycles of 84 hours a week (12 hours/day for 7 days) followed by 7 days off. Daily workhours were between 0700 and 1900, including a sedentary 15-minute transport to and from an off shore location in the middle of the Øresund straight. The second group ( $\mathrm{N}=25)$ worked 40 hours a week ( 8 hours a day for 5 days) between 0700 and 1530 at an onshore location in the harbor. The mean age of the 84-hour group was 39 (SD 10.4, range 20-60) years. The mean age of the 40-hour group was 44 (SD 13.1, range 24-65) years. The mean body mass index was 24.6 (SD 3.7) kg/m² for the 84-hour group and 27.5 (SD $5.2) \mathrm{kg} / \mathrm{m}^{2}$ for the 40-hour group. The participants were identified in collaboration with the employer, and inclusion in the groups was determined by working for one of the five company supervisors that were in charge of the participants on the different worksites. Most of the participants were from the local region and returned home after each workday. About one-fifth $(\mathrm{N}=10)$ of the participants in the 84-hour group commuted on a weekly basis as they came from more distant parts of Sweden. The mean age for this subgroup was 40 (SD 6) years, and the mean body mass index was 24.4 (SD 3.5) $\mathrm{kg} / \mathrm{m}^{2}$. During the workweek these long-distance commuters shared ordinary apartments two by two in the vicinity of the transport harbor. Both groups were engaged in heavy construction work, involving concrete work and steel reinforcement. The main task for the 84hour group was to build the two H-pylons (rising 204 meters above sea level), which support the doubledecked cable-stayed highway and railroad bridge. The 40-hour group on shore made the bridge components on which the railroad tracks rest (ie, the railroad trough). For both groups there were three scheduled breaks during the workday (ie, morning, lunch, and afternoon). Both the morning and afternoon break lasted 15 minutes, whereas the lunch break lasted 30 minutes. Due to the location of the work sites, unplanned interruptions because of disturbances in logistics or bad weather occurred more frequently for the 84-hour group.

The participants in both groups were engaged to a similar degree in a mixture of common leisure-time activities, as revealed by their responses to 17 items following a question phrased: "Do you usually engage in the following activities in your leisure time?" Items were responded to on a 3-point scale: (i) yes, often, (ii) yes, occasionally, and (iii) no, never. The activities asked for were farming, fishing or hunting, taking care of one's own small business, doing other types of extra work, resting and recovering, watching television or listening to the radio, visiting the movie theater, doing 
housework, taking care of children, reading, visiting friends and relatives, acting as a host for friends and relatives, window shopping and visiting malls, participating in courses and study circles, participating in singing or music groups, participating in sports and exercise, and participating in other hobbies (eg, woodwork, sailing, community work, etc). Pearson chi-square tests showed that window shopping and visiting malls were somewhat more prevalent in the 84-hour group. The prevalence of the participants reporting that they at least occasionally had to take care of their own small business was below $5 \%$ in both groups. Altogether, 19 persons $(38 \%)$ in the 84-hour group and 6 persons (24\%) in the 40-hour group reported that they at least occasionally did extra work during their leisure time. A total of 40 persons $(80 \%)$ in the 84-hour group and 15 persons (60\%) in the 40-hour group reported that they at least occasionally engaged in sports and exercise.

The basic questionnaire was responded to individually at home, or at work, depending on the participants' preferences. Blood samples were consecutively obtained from the 84-hour group on workdays 1, 5, and 7 and from the 40-hour group on workdays 1 and 5. Blood was drawn from cubital veins in the morning prior to the start of work (between 0615 and 0645) in the locker rooms. When the sampling was initiated, the 84-hour group had worked for approximately 6 months. The sampling was initiated at the end of March during daylight conditions.

\section{Biological measures}

We selected the biological markers with the aims of evaluating exposure and adaptation to work and determining potential health effects. The following biomarkers were used: cholesterol, cortisol, dehydroepiandrosterone, melatonin, prolactin, testosterone, and uric acid. All of the samples were nonfasting, and the specimens were handled according to standard laboratory procedures. Serum was separated and kept frozen until the sampling had been completed. All of the biomarkers (except melatonin) were analyzed as routine analyses in the departments of clinical chemistry at the University Hospital in Lund and Malmö, Sweden. Melatonin was analyzed as a batch at the Department of Clinical Neurochemistry in Lund.

Cholesterol. The total concentration was analyzed with a Hitachi auto analyzer 917 (Roche, Basel, Switzerland). The coefficient of variation was $<0.8 \%$ for both within and between runs.

Cortisol. Cortisol was analyzed with a radioimmunoassay (RIA) method. The coefficient of variation was $<5 \%$ for within runs and $<7 \%$ for between runs, at concentrations between 95 and $800 \mathrm{nmol} / \mathrm{l}$ (RIA, Orion Diagnostic, Espoo, Finland).
Dehydroepiandrosterone. Dehydroepiandrosterone (DHEA) was analyzed with RIA according to an inhouse method. The coefficient of variation was $16.2 \%$ for a concentration of $1.6 \mu \mathrm{mol} / \mathrm{l}$ and $9.6 \%$ for a concentration of $6.8 \mu \mathrm{mol} / \mathrm{l}$, and $3.7 \%$ for a concentration of $18.4 \mu \mathrm{mol} / \mathrm{l}(12)$.

Melatonin. Melatonin was analyzed with an RIA method. The detection limit was $0.3 \mathrm{ng} / \mathrm{l}$. The linear performance was between 0.5 and $50 \mathrm{ng} / \mathrm{l}$. The coefficient variation was $<11 \%$ at a concentration of $1.9 \mathrm{ng} / \mathrm{l}$, and $10 \%$ at a concentration of $18.9 \mathrm{ng} / \mathrm{l}$ (Bühlmann Melatonin RIA kit; Bühlmann Laboratories, Allschwil, Switzerland).

Prolactin. Prolactin was analyzed with the AutoDELFIA prolactin kit (Wallac Oy; now PerkinElmer, Norton, $\mathrm{OH}$, USA). The coefficient of variation was $\leq 4 \%$ for within runs and $\leq 3.6 \%$ for between runs, at concentrations of $11-35 \mu \mathrm{mol} / \mathrm{l}$.

Testosterone. The total concentration (ie, the buffer of testosterone bound to the sex hormone binding globulin, as well as the biologically nonbound active fraction, which constitutes $2 \%$ to $3 \%$ of the total amount) was analyzed with RIA according to an in-house method. The coefficient of variation was $<10.6 \%$ at a concentration of $2.5 \mathrm{nmol} / \mathrm{l}, 7.1 \%$ at a concentration of $7.5 \mathrm{nmol} / \mathrm{l}$, and $10.3 \%$ at a concentration of $16.1 \mathrm{nmol} / \mathrm{l}$ (12).

Uric acid. Uric acid was analyzed with a Hitachi auto analyzer 917 (Roche). The coefficient of variation was $<0.8 \%$ for both within runs and between runs.

\section{Questionnaire data}

Demand and control questions. In accordance with the demand and control model (13), five items assessed the participant's job demands (Chronbach's $\alpha=0.60$ ), and six items assessed job control (Chronbach's $\alpha=0.60$ ). The items were formulated as statements to which the the responses indicated the degree of agreement $(1=$ yes, often, $2=$ yes, sometimes, $3=$ no, rarely, $4=$ no, virtually never). A higher mean score indicated more perceived job demands in terms of the workpace, effort, time constraints, and conflicting demands or more perceived job control in terms of skill discretion and decision authority.

Diurnal type scale. Whether the participants were morning or evening persons was determined with seven items asking about individual preferences concerning wakeup times, time for going to bed, what time during the evening symptoms of sleepiness typically first occur, 
and how long it takes to wake up in the morning (Chronbach's $\alpha=0.75$ ) (14). Items were responded to on various 4-point scales. A higher mean score represented being more of a morning person.

Positive psychosocial factors at work. The presence of positive psychosocial factors at work was assessed with six items (Chronbach's $\alpha=0.80$ ). The items were formulated as statements to which the responses indicated degree of agreement $(1=$ applies completely, $2=$ applies fairly well, 3 = does not apply particularly well, 4 = does not apply at all). A higher mean score indicated more positive factors at work in terms of perceived support from co-workers and management, a quiet and relaxed atmosphere, strong bonding between co-workers, and a tolerance for people experiencing bad days at work.

Subjective health complaints. The frequency of 25 common health complaints experienced during the last 6 months was assessed with a subjective health complaint scale similar to the scale used in the Ursin Health Inventory/Subjective Health Complaints (15). The items were primarily grouped according to the organ systems, resulting in the following five dimensions: (i) anxiety or depression (7 items, Chronbach's $\alpha=0.87$ ), (ii) bodily aches and stiffness ( 4 items, Chronbach's $\alpha=0.51$ ), (iii) cardiovascular symptoms (3 items, Chronbach's $\alpha=0.50$ ), (iv) intestinal problems ( 8 items, Chronbach's $\alpha=0.67$ ), and (v) mental fatigue ( 3 items, Chronbach's $\alpha=0.68)$. The participants responded to the items on a 5 -point Likert scale [ $1=$ never, $2=$ rarely (a few times), $3=$ sometimes (once or twice a week), 4 = most of the time (a couple of times a week), and $5=$ always (every day, more or less)].

Symptoms of sleepiness. Symptoms of sleepiness during the last 6 months was assessed with the Karolinska Sleep Questionnaire (KSQ) (16). An awakening score was calculated as the mean score of the following three items: (i) ease of awakening, (ii) exhaustion at awakening, and (iii) whether the sleep was refreshing (Chronbach's $\alpha=0.68$ ). A disturbed sleep score was calculated as the mean score of four symptom items asking about (i) difficulties falling asleep, (ii) repeated awakenings with difficulties to go back to sleep, (iii) premature awakening, and (iv) disturbed or restless sleep (Chronbach's $\alpha=0.76$ ). A sleepiness complaint score was formed by calculating the mean score of five items that asked about how many times the participants had had the following experiences during the last 6 months: (i) fought to stay awake, (ii) used power-naps during leisure time, (iii) involuntary episodes of falling asleep during workhours, (iv) felt irritation or strain of the eyes, (v) experienced sleepiness during work and leisure time (Chronbach's $\alpha=0.68$ ).
The participants responded to all of the sleep items on a 5-point Likert scale, similar to the subjective health complaints scale. For all of the indices, higher scores indicated more frequent experiences with the specific symptoms.

Work-home conflict. Negative spillover between work and homelife was assessed with 11 items, which were responded to on a 4-point Likert scale, reflecting the degree to which the workhours allowed enough time for various social interactions or activities ( 1 = enough, 2 = almost enough, 3 = not enough, 4 = not near enough). By the procedure of reversing the individual items, two indices were calculated reflecting (i) insufficient time for social activities ( 8 items, Chronbach's $\alpha=0.92$ ) and (ii) insufficient time for social interaction (3 items, Chronbach's $\alpha=0.63$ ).

\section{Ethics}

All of the participants gave their written informed consent to participate. The Ethics Committee of Lund University approved the study protocol (LU 63-98).

\section{Statistical analysis}

P-values below 0.05 were considered statistically significant. The statistical calculations were conducted with SPSS 12.0 (SPSS Inc, Chicago, IL, USA). The questionnaire data was, for the most part, evaluated with independent sample t-tests, and the assumption of equal variances across groups was tested with Levene's test. Using the general linear mixed models module, we evaluated the biological markers using a repeated-measures design. The categorical predictors were workday (workdays 1, 5, and 7) and group (84-hour versus 40-hour). The dependent variables were the biomarkers. Because a high ratio of cortisol to testosterone (CT ratio) is often conceived to be an endocrine reaction indicative of a stress reaction (17), this ratio was also used as a dependent variable. Only data from the participants who contributed at least two blood samples were included in the analyses. In a first step, a between-group analysis including workdays 1 and 5 was performed. The factor terms were entered simultaneously with the interaction term group by workday. If the interaction failed to reach statistical significance, it was removed. For each analysis, age and body mass index were entered as covariates. If a regression with $\mathrm{P}<0.20$ was found between a covariate and an outcome, the former was retained in the final model. For the final model, posthoc testing to illuminate pairwise differences was carried out with the least significance difference procedure for the estimated marginal means. In a second step, analyses similar to those already presented were conducted involving all 
of the workdays and the 84-hour group only. The models were solved using the restricted maximum likelihood (REML) method, and Schwarz's Bayesian criterion was used to guide the selection of the covariance structure. In most cases, a compound symmetry covariance structure provided the best fit. Only when changes in the cortisol concentration were analyzed across all three workdays in the 84-hour group did a first-order autoregressive covariance structure outperform the compound symmetry structure. Residual plots were used to identify potential outliers and deviations from normality assumptions. Only melatonin showed a non-normal distribution, the residual variances increasing for higher levels of measurements. This non-normality was corrected to fit a linear model by means of a logarithmic transformation (nlog). The log-transformed variable was antilogged and converted back to the original scale after the testing. To examine the relationship between the subjective reports of demand and control and the biomarkers, we extended the statistical models to include demand and control and their interaction as continuous covariates. The results from the continuous variables are presented as raw beta scores. To facilitate the comparisons between the biomarkers and the questionnaire data, as well as across studies, the results have also been expressed as standard deviation units (z-scores).

\section{Results}

\section{Biological measures}

For each biomarker, the crude mean values and standard deviations are presented in table 1.

\section{Tests of differences between the groups between workdays 1 and 5}

There was a statistically significant group for the workday interaction only for the $\mathrm{CT}$ ratio $(\mathrm{P}=0.012)$. A posthoc evaluation showed that the 40-hour group had a higher CT ratio than the 84-hour group for workday 1 [CT ratio $6.3,95 \%$ confidence interval $(95 \%$ CI) $0.4-$ 12.3] $(\mathrm{P}=0.035)$ but a similar $\mathrm{CT}$ ratio for workday 5 (CT ratio $1.4,95 \% \mathrm{CI}-4.6-7.3)(\mathrm{P}=0.654)$. The other interaction $\mathrm{P}$-values ranged from 0.064 (cortisol) to 0.889 (melatonin). The nonstatistically significant cortisol interaction indicated that the 40-hour group started out with higher cortisol levels than the 84-hour group on day 1 but had lower values on day 5. Furthermore, a statistically significant main effect of group showed that the 84-hour group, on the average, had higher melatonin concentrations than the 40-hour group. Expressed in standard deviation units this difference was $0.7 \mathrm{z}$ scores (95\% CI 0.3-1.2). A statistically significant main effect of workday showed that the cortisol, melatonin, and cholesterol concentrations decreased between workdays 1 and 5 (table 2). Expressed in standard deviation units this effect corresponded to -0.4 (95\% CI -0.60$-0.2),-0.5(95 \%$ CI $-0.7--0.3)$, and $-0.2(0.0-0.3) \mathrm{z}-$ scores, respectively.

The higher melatonin concentrations in the 84-hour group suggested that this group may have had an earlier circadian phase. Therefore, the melatonin score was also introduced as a continuous covariate in the statistical modeling. The melatonin-adjusted results showed that the overall pattern essentially remained the same and only minor changes in the mean estimates were noted (data not shown). In addition, since cholesterol and DHEA can be viewed as precursors of certain steroid hormones (albeit DHEA is a steroid hormone), the statistical modeling was also extended to include cholesterol and DHEA as continuous covariates in the between-group analyses. The results showed only slight changes in the estimates and P-values (data not shown).

\section{Tests of differences across workdays 1 to 7 in the 84- hour group}

A statistically significant main effect of workday was observed for the cortisol, testosterone, melatonin, prolactin, and cholesterol levels (table 3). All of the hormone

Table 1. Crude means and standard deviations of the biochemical markers. (DHEA $=$ dehydroepiandrosterone, CT ratio $=$ cortisol-totestosterone ratio)

\begin{tabular}{|c|c|c|c|c|c|c|c|c|c|c|c|c|c|c|c|c|}
\hline \multirow[t]{2}{*}{ Group } & \multicolumn{2}{|c|}{$\begin{array}{l}\text { Cholesterol } \\
(\mathrm{mmol} / \mathrm{l})\end{array}$} & \multicolumn{2}{|c|}{$\begin{array}{l}\text { Cortisol } \\
(\mathrm{nmol} / \mathrm{l})\end{array}$} & \multicolumn{2}{|c|}{$\begin{array}{c}\text { DHEA } \\
(\mu \mathrm{mol} / \mathrm{l})\end{array}$} & \multicolumn{2}{|c|}{$\begin{array}{l}\text { Melatonin } \\
(\mathrm{ng} / \mathrm{l})\end{array}$} & \multicolumn{2}{|c|}{$\begin{array}{l}\text { Prolactin } \\
\quad(\mu \mathrm{g} / \mathrm{l})\end{array}$} & \multicolumn{2}{|c|}{$\begin{array}{l}\text { Testosterone } \\
(\mathrm{nmol} / \mathrm{l})\end{array}$} & \multicolumn{2}{|c|}{$\begin{array}{l}\text { Uric acid } \\
(\mu \mathrm{mol} / /)\end{array}$} & \multicolumn{2}{|c|}{$\begin{array}{l}\mathrm{CT} \\
\text { ratio }\end{array}$} \\
\hline & Mean & SD & Mean & SD & Mean & SD & Mean & SD & Mean & SD & Mean & SD & Mean & $\mathrm{SD}$ & Mean & SD \\
\hline \multicolumn{17}{|l|}{ 84-hour group } \\
\hline Workday $1(\mathrm{~N}=49)$ & 5.25 & 1.08 & 558 & 111 & 6.03 & 2.45 & 27.69 & 23.97 & 8.04 & 3.26 & 19.75 & 4.99 & 315 & 57 & 30.3 & 10.7 \\
\hline Workday $5(\mathrm{~N}=47)$ & 5.07 & 1.03 & 532 & 107 & 6.06 & 2.45 & 18.28 & 18.19 & 7.51 & 2.64 & 18.66 & 5.30 & 323 & 54 & 30.8 & 11.7 \\
\hline Workday $7(\mathrm{~N}=46)$ & 4.94 & 1.05 & 497 & 114 & 5.96 & 2.53 & 15.60 & 14.22 & 7.15 & 2.93 & 17.56 & 4.63 & 314 & 47 & 29.6 & 8.24 \\
\hline \multicolumn{17}{|l|}{ 40-hour group } \\
\hline Workday $1(\mathrm{~N}=24)$ & 5.44 & 0.72 & 558 & 144 & 6.25 & 2.50 & 12.49 & 11.74 & 7.46 & 4.88 & 15.43 & 5.40 & 334 & 64 & 38.8 & 11.9 \\
\hline Workday $5(\mathrm{~N}=23)$ & 5.36 & 0.73 & 475 & 145 & 6.20 & 2.61 & 6.94 & 5.99 & 7.35 & 4.63 & 15.19 & 5.38 & 337 & 65 & 33.5 & 11.8 \\
\hline
\end{tabular}


Table 2. Main effects of group and workday. The figures have been rounded to one decimal. The covariates were retained in the model if $\mathrm{P}<0.20$. (DHEA = dehydroepiandrosterone)

\begin{tabular}{|c|c|c|c|c|c|c|c|c|}
\hline \multirow[t]{3}{*}{ Biological marker } & \multicolumn{4}{|c|}{ Group } & \multicolumn{4}{|c|}{ Workday } \\
\hline & \multirow{2}{*}{$\begin{array}{l}\text { 40-hour } \\
\text { group } \\
\text { (reference } \\
\text { level) }\end{array}$} & \multicolumn{2}{|c|}{ 84-hour group } & \multirow{2}{*}{$\begin{array}{c}\text { Type III } \\
\text { F-test } \\
\text { (P-value) }\end{array}$} & \multirow{2}{*}{$\begin{array}{c}\text { Workday } 1 \\
\text { (reference } \\
\text { level) }\end{array}$} & \multicolumn{2}{|c|}{ Workday 5} & \multirow{2}{*}{$\begin{array}{l}\text { Type III } \\
\text { F-test } \\
\text { (P-value) }\end{array}$} \\
\hline & & $\begin{array}{l}\text { Change in } \\
\text { reference } \\
\text { level }\end{array}$ & $95 \% \mathrm{Cl}$ & & & $\begin{array}{l}\text { Change in } \\
\text { reference } \\
\text { level }\end{array}$ & $95 \% \mathrm{Cl}$ & \\
\hline Cholesterol (mmol/l) & 5.2 & 0.0 & $-0.4-0.5$ & $0.913^{a, b}$ & 5.3 & -0.1 & $-0.3--0.0$ & $0.009 a, b$ \\
\hline Cortisol (nmol/l) & 538.4 & -6.4 & $-63.8-50.9$ & $0.824^{a, b}$ & 557.9 & -45.4 & $-68.5--22.3$ & $<0.001^{a, b}$ \\
\hline DHEA $(\mu \mathrm{mol} / \mathrm{l})$ & 6.6 & -0.8 & $-1.8-0.1$ & $0.081^{a}$ & 6.2 & 0.0 & $-0.4-0.4$ & $0.952^{a}$ \\
\hline Melatonin (ng/l) & 6.8 & +8.3 & $3.0-16.6$ & $<0.001^{a}$ & 13.2 & -5.5 & $-8.2--3.3$ & $<0.001^{\text {a }}$ \\
\hline Prolactin $(\mu \mathrm{g} / \mathrm{l})$ & 8.0 & -0.4 & $-2.1-1.4$ & $0.668 \mathrm{a}, \mathrm{b}$ & 8.0 & -0.4 & $-0.1-1.0$ & $0.122^{a, b}$ \\
\hline Testosterone (nmol/l) & 16.6 & +1.9 & $-0.4-4.3$ & $0.105^{a, b}$ & 17.9 & -0.6 & $-1.3-0.1$ & $0.106^{a, b}$ \\
\hline Uric acid ( $\mu \mathrm{mol} / \mathrm{l})$ & 324 & -3.2 & $-29.0-22.7$ & $0.807^{b}$ & 320 & +5.6 & $-5.8-17.1$ & $0.328^{b}$ \\
\hline
\end{tabular}

Age-adjusted mean differences between the groups or workdays.

b Body mass index adjusted for the mean differences between the groups or workdays.

Table 3. Test of differences between the workdays in the 84-hour group ( $N=47)$. The figures have been rounded to one decimal. The covariates were retained in the model if $\mathrm{P}<0.20$. (DHEA $=$ dehydroepiandrosterone, $C T$ ratio $=$ cortisol-to-testosterone ratio)

\begin{tabular}{|c|c|c|c|c|c|c|}
\hline \multirow[t]{2}{*}{ Biological marker } & \multirow{2}{*}{$\begin{array}{c}\text { Workday } 1 \\
\text { (reference } \\
\text { level) }\end{array}$} & \multicolumn{2}{|c|}{ Workday 5} & \multicolumn{2}{|c|}{ Workday 7} & \multirow{2}{*}{$\begin{array}{l}\text { Type III } \\
\text { F-test } \\
\text { (P-value) }\end{array}$} \\
\hline & & $\begin{array}{c}\text { Change in } \\
\text { reference } \\
\text { level }\end{array}$ & $95 \% \mathrm{Cl}$ & $\begin{array}{l}\text { Change in } \\
\text { reference } \\
\text { level }\end{array}$ & $95 \% \mathrm{Cl}$ & \\
\hline Cholesterol (mmol/l) & 5.2 & $-0.2^{a}$ & $-0.3--0.0$ & $-0.3^{b}$ & $-0.4--0.1$ & $<0.001^{c}$ \\
\hline Z-score & 0 & -0.2 & $-0.3-0.0$ & -0.2 & $-0.4--0.1$ & \\
\hline Cortisol (nmol/l) & 559 & -29.4 & $-59.0-0.3$ & $-53.9^{b}$ & $-91.4--16.4$ & 0.020 \\
\hline Z-score & 0 & -0.3 & $-0.5-0.0$ & -0.5 & $-0.8--0.1$ & \\
\hline DHEA $(\mu \mathrm{mol} / \mathrm{l})$ & 6.0 & +0.1 & $-0.5-0.7$ & -0.1 & $-0.6-0.5$ & $0.845^{c}$ \\
\hline Z-score & 0 & 0.0 & $-0.2-0.3$ & 0.0 & $-0.2-0.2$ & \\
\hline Prolactin $(\mu \mathrm{g} / \mathrm{l})$ & 8.3 & -0.6 & $-1.3-0.1$ & $-1.1^{b}$ & $-1.8--0.4$ & $0.010^{c}$ \\
\hline Z-score & 0 & -0.2 & $-0.5-0.0$ & -0.4 & $-0.6--0.1$ & \\
\hline Testosterone (nmol/l) & 19.7 & $-0.9^{a}$ & $-1.7--0.1$ & $-2.2^{b, d}$ & $-3.0--1.4$ & $<0.001^{e}$ \\
\hline Z-score & 0 & -0.2 & $-0.3-0.0$ & -0.4 & $-0.6--0.3$ & \\
\hline Melatonin $(\mathrm{ng} / \mathrm{l})^{\dagger}$ & 20.8 & $-8.8^{a}$ & $-13.5--5.5$ & $-9.3^{b}$ & $-14.1--5.5$ & $<0.001$ \\
\hline Z-score & 0 & -0.6 & $-0.8--0.4$ & -0.6 & $-0.8--0.4$ & \\
\hline Uric acid $(\mu \mathrm{mol} / \mathrm{l})$ & 313 & +7.8 & $-4.2-19.9$ & +0.2 & $-11.9-12.3$ & $0.430 \mathrm{e}$ \\
\hline Z-score & 0 & +0.1 & $-0.1-0.4$ & 0.0 & $-0.2-0.3$ & \\
\hline CT ratio & 30.6 & -0.1 & $-2.3-2.4$ & -0.4 & $-3.4-2.6$ & $0.966^{e}$ \\
\hline Z-score & 0 & 0.0 & $-0.2-0.2$ & 0.0 & $-0.3-0.3$ & \\
\hline
\end{tabular}

a Posthoc pairwise comparisons, workday 1 versus workday $5, \mathrm{P}<0.05$.

b Posthoc pairwise comparisons, workday 1 versus workday $7, \mathrm{P}<0.05$.

c Adjusted for age.

d Posthoc pairwise comparisons, workday 5 versus workday $7, \mathrm{P}<0.05$.

e Adjusted for body mass index.

$\mathrm{f}$ The melatonin values are antilogged.

concentrations were lower on workday 7 than on workday 1. Typically, the hormone concentrations on workdays 5 and 7 did not deviate from each other. Only the testosterone concentrations decreased between workday 5 and 7. Adjusting for weekly commuting by entering this between-participant factor in the statistical analyses, or by removing it from the statistical analyses, did not change this general pattern. However, the group of weekly commuters showed, on the average, higher cortisol concentrations (97 nmol/1, 95\% CI 35-159) $(\mathrm{P}=0.003)$, lower uric acid concentrations $(-33 \mu \mathrm{mol} / \mathrm{l}, 95 \% \mathrm{CI}-60--7)(\mathrm{P}=0.014)$, and a trend towards higher cholesterol concentrations $(0.64 \mathrm{mmol} / \mathrm{l}$,
95\% CI -0.02-1.31) $(\mathrm{P}=0.058)$. When compared with the rest of the 84-hour group, the group of weekly commuters also showed a different pattern of prolactin and testosterone secretion across the workdays (interaction P-values $=0.002$ and 0.036 , respectively) as they had declining levels only between workdays 1 and 5 but remained stable between workdays 5 and 7 or even had slightly increased (prolactin) (data not shown).

\section{Questionnaire data}

The 84-hour group reported higher job control scores but similar job demand scores as the 40-hour group. 
Both groups reported similar levels of influence of work on social interactions and activities (table 4). There was no group difference in perceived presence of positive psychosocial factors at work, subjective health complaints, or sleep disturbances (table 5).

The group of weekly commuters reported fewer sleep disturbances $(\mathrm{P}=0.028)$ than the rest of the workers in the 84-hour group, and they were more content with their available time for social interactions $(\mathrm{P}=0.027)$ (data not shown).

\section{Relationship between self-reported psychosocial conditions and biomarkers}

When the demand and control scores and their interaction as continuous covariates in the statistical modeling were introduced in order to examine their influence on the between-group comparisons, no substantial change in the biomarker estimates was noted. For the most part, only minor changes in the P-values were noted between groups (data not shown). However, the analyses revealed a statistically significant interaction effect between demand and control scores and cortisol concentrations ( $\beta=-164 \mathrm{nmol} / 1,95 \% \mathrm{CI}-321--7.2)(\mathrm{P}=0.041)$. To check whether this regression coefficient was of an approximately similar strength in both groups, we repeated the calculation for each group independently. This analysis revealed that the main effects and interaction regression coefficients for the 40-hour group had $\mathrm{P}$-values well above 0.900 , whereas the P-values in the 84-hour group were all below 0.005 .

When the analyses for the 84-hour group and all workdays were performed again, the same pattern was essentially repeated. Only cortisol had statistically significant regression coefficients for the interaction between the demand and control scores $(\beta=-241.5 \mathrm{nmol} / \mathrm{l}$,

Table 4. Self-reported work situation, diurnal typing, and subjective health complaints.

\begin{tabular}{|c|c|c|c|c|c|c|c|}
\hline & \multicolumn{2}{|c|}{$\begin{array}{l}\text { 84-hour group } \\
\qquad(\mathrm{N}=50)\end{array}$} & \multicolumn{2}{|c|}{$\begin{array}{l}\text { 40-hour group } \\
(\mathrm{N}=25)\end{array}$} & \multicolumn{3}{|c|}{ t-test } \\
\hline & Mean & SD & Mean & SD & $\begin{array}{c}\text { Difference } \\
\text { in raw } \\
\text { score }\end{array}$ & $\begin{array}{c}\text { Difference } \\
\text { in z } \\
\text { score }\end{array}$ & $\begin{array}{c}\mathrm{P}- \\
\text { value }\end{array}$ \\
\hline \multicolumn{8}{|l|}{ Demand and control } \\
\hline Job control (1 = low, 4 = high) & 2.89 & 0.39 & 2.63 & 0.34 & 0.26 & 0.66 & 0.007 \\
\hline Job demand (1 = low, 4 = high) & 2.55 & 0.43 & 2.43 & 0.42 & 0.12 & 0.29 & 0.235 \\
\hline Demand:control ratio (>1 = demands surpasses control) & 0.90 & 0.19 & 0.94 & 0.23 & 0.04 & -0.21 & 0.398 \\
\hline Diurnal type scale ( 1 = evening type, 4 = morning type) & 2.84 & 0.50 & 3.00 & 0.49 & -0.16 & -0.19 & 0.187 \\
\hline Positive psychosocial factors at work ( $1=$ to a less degree, $4=$ to a high degree) & 3.37 & 0.48 & 3.42 & 0.39 & -0.05 & -0.12 & 0.630 \\
\hline \multicolumn{8}{|l|}{ Subjective health complaints during the last 6 months } \\
\hline Anxiety or depression ( 1 = never, 5 = everyday) & 1.47 & 0.55 & 1.32 & 0.44 & 0.15 & 0.28 & 0.252 \\
\hline Bodily aches and stiffness ( $1=$ never, $5=$ everyday $)$ & 1.69 & 0.58 & 1.94 & 0.76 & -0.26 & -0.39 & 0.112 \\
\hline Cardiovascular symptoms ( 1 = never, 5 = everyday) & 1.10 & 0.26 & 1.22 & 0.46 & -0.12 & -0.37 & 0.210 \\
\hline Intestinal problems $(1=$ never, $5=$ everyday $)$ & 1.42 & 0.42 & 1.50 & 0.40 & -0.08 & -0.20 & 0.421 \\
\hline Mental fatigue $(1=$ never, $5=$ everyday $)$ & 1.72 & 0.56 & 1.71 & 0.63 & 0.01 & 0.02 & 0.926 \\
\hline Total score $(1=$ never, $5=$ everyday $)$ & 1.47 & 0.35 & 1.50 & 0.34 & -0.03 & -0.08 & 0.737 \\
\hline
\end{tabular}

Table 5. Self-reported sleep symptoms and work-home conflict.

\begin{tabular}{|c|c|c|c|c|c|c|c|}
\hline & \multicolumn{2}{|c|}{$\begin{array}{l}\text { 84-hour group } \\
\qquad(\mathrm{N}=50)\end{array}$} & \multicolumn{2}{|c|}{$\begin{array}{l}\text { 40-hour group } \\
\qquad(\mathrm{N}=25)\end{array}$} & \multicolumn{3}{|c|}{ t-test } \\
\hline & Mean & SD & Mean & SD & $\begin{array}{l}\text { Difference } \\
\text { in raw } \\
\text { score }\end{array}$ & $\begin{array}{l}\text { Difference } \\
\text { in z } \\
\text { score }\end{array}$ & $\begin{array}{c}\text { P- } \\
\text { value }\end{array}$ \\
\hline Bedtime & 2208 & $00: 32^{a}$ & 2226 & $00: 46^{a}$ & -0018 & -0.47 & 0.052 \\
\hline Wake-up time & 0513 & $00: 24^{a}$ & 0519 & $00: 28$ a & -0006 & -0.22 & 0.375 \\
\hline Time for falling asleep (minutes) & 10 & 8 & 12 & 10 & - & - & - \\
\hline \multicolumn{8}{|l|}{ Symptoms of sleepiness during the last 6 months } \\
\hline $\begin{array}{l}\text { Difficulties awakening }(1=\text { never, } 5=\text { almost every day }) \\
\text { Disturbed sleep score }(1=\text { never, } 5=\text { almost every day }) \\
\text { Sleepiness complaints }(1=\text { never, } 5=\text { almost every day })\end{array}$ & $\begin{array}{l}1.83 \\
1.68 \\
1.60\end{array}$ & $\begin{array}{l}0.59 \\
0.52 \\
0.54\end{array}$ & $\begin{array}{l}1.79 \\
1.67 \\
1.54\end{array}$ & $\begin{array}{l}0.71 \\
0.71 \\
0.52\end{array}$ & $\begin{array}{l}0.04 \\
0.01 \\
0.06\end{array}$ & $\begin{array}{l}0.07 \\
0.02 \\
0.10\end{array}$ & $\begin{array}{l}0.783 \\
0.932 \\
0.684\end{array}$ \\
\hline \multicolumn{8}{|l|}{ Work-home conflict } \\
\hline $\begin{array}{l}\text { Insufficient time for social activities ( } 1=\text { sufficient, } 5=\text { far from sufficient) } \\
\text { Insufficient time for social interactions ( } 1=\text { sufficient, } 5=\text { far from sufficient) }\end{array}$ & $\begin{array}{l}1.87 \\
2.37\end{array}$ & $\begin{array}{l}0.79 \\
0.95\end{array}$ & $\begin{array}{l}2.06 \\
2.12\end{array}$ & $\begin{array}{l}0.89 \\
0.96\end{array}$ & $\begin{array}{r}-0.20 \\
0.25\end{array}$ & $\begin{array}{r}-0.24 \\
0.26\end{array}$ & $\begin{array}{l}0.340 \\
0.288\end{array}$ \\
\hline
\end{tabular}

a In hours:minutes. 
95\% CI -415- -68) $(\mathrm{P}=0.007)$. The other biomarkers showed no statistically significant relationships to the demand and control scores either independently or in combination $(\mathrm{P}$-values $=0.084$ to 0.911$)$. Further evaluation with a median split procedure using the demand and control scores revealed that low demand and high control scores were associated with higher mean cortisol values than the combination of low demand and low control scores $(\mathrm{P}=0.007)$, as well as high demands and high control scores $(\mathrm{P}=0.027)$.

\section{Discussion}

Our study disclosed no obvious signs of harmful biological imbalances that accumulated throughout the 84hour workweek. Nor did the baseline questionnaire reveal any marked differences between the 84-hour and 40-hour groups as regards signs of psychosocial troubles, work-home conflicts or symptoms of sleepiness. Only on one of the many subscales included in the questionnaire did the 84-hour group deviate from the 40-hour group. This deviation showed that the 84-hour group reported a higher feeling of control than the 40-hour group. However, this difference in perceived control could not explain the observed differences in the biochemical concentrations, as noted when the demand and control scores were adjusted for in the statistical analysis. Irrespective of statistical significance, most of the biomarker concentrations decreased between workdays 1 and 5. Only the DHEA and uric acid concentrations remained fairly stable throughout the observation period. Hence, our initial theorizing that long workhours in combination with heavy work should increase activity in biological systems that promote immediate energy expenditure while inhibiting systems involved in restitution received no support. The most noticeable group difference was instead the 84-hour group's higher melatonin concentrations. As the groups had similar sleep lengths during the workweek and started work at the same time and the sampling was performed at similar times and during daylight conditions, the observed group difference was not likely explained by different sleep behavior during the workweek (18). The elevated melatonin concentrations, particularly on workday 1 , for the 84-hour group suggests a delayed circadian phase, that is, a later peak in melatonin concentrations the night just before the measurement. The delay is probably related to the week off, and it is likely that the participants changed their sleep habits during this week. Earlier rising, as well as exposure to outdoor light during the workweek, would have advanced the melatonin peak. However, whether melatonin changes over an extended time period may negatively influence other physiological systems that are of a rhythmic nature, for example, the cardiovascular and digestive systems, is debatable.

The normal, and during the workweek fairly stable, concentrations of uric acid implies that the 84-hour schedule did not create more cell and tissue breakdown than the 40-hour schedule, and our observations of normal but decreasing cholesterol concentrations during the workweek in both groups probably signifies that the workers consumed fewer calories than their bodies used. The falling cholesterol levels suggest that a higher intake of calories during workdays might be appropriate. Alternatively, the falling cholesterol concentrations may signal a shift in dietary regimen. Possibly, the workers eat less fatty foods during workdays.

Removing the small subgroup of weekly commuters in the 84-hour group (or statistically adjusting for this between-participant effect) did not change the overall pattern of results. Instead, the subgroup analyses revealed that the group of weekly commuters reported fewer sleep problems and had lower concentrations of uric acid. In addition, the trend towards higher cholesterol concentrations, and the stable testosterone concentrations between workdays 5 and 7, probably reflects better recovery among the weekly commuters than among the rest of the 84-hour group. The weekly commuters' generally higher cortisol concentrations probably indicate that they woke up later (18). Under the present circumstances, with a fixed sampling period just prior to the start of work, a later awakening is likely to have increased the likelihood to obtain samples that are closer to the peak of the cortisol awakening response, which is typically thought to occur in the first $30 \mathrm{~min}$ utes after awakening (19).

Despite the small sample sizes, it is clear that our study had sufficient power to detect fairly small effects, as indicated by the z-scores. That the ratio of participants in the two groups was 1:2 was not likely to result in any substantial loss in statistical power (20). Another factor of importance for understanding the results is the knowledge that different occupations may attract people with certain characteristics. Thus the allocation of the workforce is typically not random even if some chance may well be involved. Whether the selection processes were mainly influenced by organizational demands or by individual preferences is of less concern; the net result is a nonrandom allocation. For this reason it is important to remember that the participants in our study were first and foremost likely to be representative of their own and similar lines of work.

A concern when the results of our study are interpreted is also the determination of the extent to which the observed shifts in the morning levels of the hormones and biochemical markers can be attributed to differences between the two work schedules. Obviously, 
any measured concentration of a biochemical substance or hormone will always reflect both acute and lasting adaptations to circumstances that originate within and outside a person. Some factors that may have influenced the measured morning concentrations are, for example, diurnal rhythms, breakfast, and the effects of traveling to work. However, none of these factors are believed to be differentially distributed in such a way that they might invalidate the group comparisons or comparisons across workdays. As regards the potential impact of time of day on hormone concentrations, the narrow range in which the samples were obtained and the similar wakeup times and bedtimes in the 84- and 40-hour groups make us believe that the diurnal rhythm was under control. It is however clear that the absolute concentrations of some of the hormones, such as cortisol and testosterone, would be considerably different if they were measured, for example, after work or later in the evening. Yet, it may be recognized that it would have been beneficial to obtain supplementary biochemical measurements during, for example, a time period prior to the start of the building project and a time period after the project had finished. Due to the short notice of the project, however, the use of such a design was not feasible. It may also be noted that a denser sampling schedule for the biochemical measures would have made it possible to study both the accumulated effects and the degree of physiological activation during and after work more thoroughly.

Another complexity for understanding the results of our study is our past observation, made with ambulatory electrocardiography monitoring, that the 40-hour group worked at a higher percentage of their cardiovascular capacity. This finding led us to the conclusion that we, despite great effort, had been unsuccessful in finding a control group with optimal comparability as regards actual workload or work effort (9). Even if the groups had comparable worktasks with similar hazards (ie, primarily iron binding and concreting), it seems that other factors, perhaps participant motivation, work strategies and possibly management style, influenced individual effort and, accordingly, the cardiovascular output. Hence, long workhours and extended workweeks need not be physiologically more challenging than an ordinary workweek and regular workhours. However, this possibility does not automatically imply that the 84hour schedule is safe. Indeed, the gradual decline in testosterone concentrations raises, in its own right, some concern. Because testosterone stimulates tissue repair and development, this decline may be a sign of poor recovery. Knowing that both groups of participants slept approximately 1 hour less during the workweek than on days off (18) and that testosterone is dependent on sleep length (19) suggests that short sleep contributed to the testosterone decrease. That no fall was observed in the 40-hour group may either signal that the 40-hour group was unaffected by their work or that the testosterone levels had stabilized and that 2 days off was not enough time to recuperate. That the generally higher testosterone concentrations in the 84-hour group should reflect a selection effect due to fitness seems unlikely in view of our previous observations of similar heart rates during rest (9). However, it cannot be ruled out that the group difference was related to the 84-hour group's extended leave between work periods. Yet the mean concentrations in testosterone were well within the normal range of healthy male adults and did not trigger an immediate medical decision. Nonetheless, the fact that the decrease in testosterone concentrations in the 84-hour group was of similar magnitude between workdays 1 and 5 as the decrease between workdays 5 and 7 draws attention. In view of the shorter time span, one could speculate whether this finding reflects a physiological turning point and whether it would be appropriate to introduce a maximum limit for the number of consecutive 12-hour workshifts to no more than 5 days in a row. This view is strengthened by the observation that the subgroup of weekly commuters, who slept about 30minutes longer and reported fewer sleep complaints (18), showed no similar decline.

In conclusion, working of one's own free will on an 84-hour workweek schedule with physically and mentally demanding job assignments does not necessarily induce greater physiological strain than working with similar tasks on an ordinary 40-hour workweek schedule. However, working on an 84-hour schedule in periods beyond the ordinary 40-hour week results in signs of functional changes in hormonal and biochemical regulation. The changes cannot, from an individual health perspective, in the short-term be considered as a sign of unfavorable hormonal and biochemical disturbances to such an extent that they would require immediate attention. Instead the changes are to be seen as wear and tear that is probably attended to with proper recovery and proper food intake. The potential significance of the observed functional changes in hormonal and biochemical regulation with respect to poor health in the longterm remains to be evaluated.

\section{Acknowledgments}

AFA insurances, Stockholm, Sweden, financially supported this study.

Our gratitude is expressed to the participants, as well as to the past and present members of our technical staff, who contributed with collection of data and various administrative tasks. 


\section{References}

1. Knutsson A. Health disorders of shift workers. Occup Med (Lond). 2003;53:103-8.

2. Tenkanen L, Sjöblom T, Kalimo R, Alikoski T, Härmä M. Shift work, occupation and coronary heart disease over 6 years of follow-up in the Helsinki Heart Study. Scand J Work Environ Health. 1997;23(4):257-65.

3. Tüchsen F, Jeppesen HJ, Bach E. Employment status, nondaytime work and gastric ulcer in men. Int $\mathrm{J}$ Epidemiol. 1994;23:365-70.

4. Spurgeon A, Harrington JM, Cooper CL. Health and safety problems associated with long working hours: a review of the current position. Occup Environ Med. 1997;54:367-75.

5. van der Hulst M. Long workhours and health [review]. Scand J Work Environ Health. 2003;29(3):171-88.

6. Carusco C, Hitchcock E, Dick R, Russo J, Schmit J. Overtime and extended work shifts: recent findings on illnesses, injuries and health behaviors. Cincinnati $(\mathrm{OH})$ : National Institute for Occupational Safety and Health; 2004. No 2004-143.

7. Hannerz H, Spangenberg S, Tüchsen F, Albertsen K. Disability retirement among former employees at the construction of the Great Belt Link. Public Health. 2005;119:301-4.

8. Tüchsen F, Hannerz H, Spangenberg S. Mortality and morbidity among bridge and tunnel construction workers who worked long hours and long days constructing the Great Belt Fixed Link. Scand J Work Environ Health. 2005;31 suppl 2:22-6.

9. Persson R, Ørbæk P, Ursin H, Kecklund G, Österberg K, Åkerstedt T. Effects of the implementation of an 84-hour workweek on neurobehavioral test performance and cortisol responsiveness during testing. Scand J Work Environ Health. 2003;29(4):261-9.

10. McEwen BS, Seeman T. Protective and damaging effects of mediators of stress. Elaborating and testing the concepts of allostasis and allostatic load. Ann N Y Acad Sci. 1999;896:3047.
11. Seeman TE, McEwen BS, Rowe JW, Singer BH. Allostatic load as a marker of cumulative biological risk: MacArthur studies of successful aging. Proc Natl Acad Sci U S A. 2001;98:4770-5.

12. Thorell J, Larsson SM. Radioimmunoassay and related techniques. Methodology and clinical applications. St Louis (MI): CV Mosby Company; 1978. p. 131-6.

13. Karasek R, Theorell T. Healthy Work: stress productivity and the reconstruction of working life. New York (NY): Basic Books; 1990

14. Torsvall L, Åkerstedt T. A diurnal type scale: construction, consistency and validation in shift work. Scand J Work Environ Health. 1980;6(4):283-90.

15. Eriksen HR, Ihlebaek C, Ursin H. A scoring system for subjective health complaints (SHC). Scand J Public Health. 1999;27:63-72.

16. Åkerstedt T, Knutsson A, Westerholm P, Theorell T, Alfredsson L, Kecklund G. Sleep disturbances, work stress and work hours: a cross-sectional study. J Psychosom Res. 2002;53:7418.

17. Smith GD, Ben Shlomo Y, Beswick A, Yarnell J, Lightman S, Elwood P. Cortisol, testosterone, and coronary heart disease: prospective evidence from the Caerphilly study. Circulation. 2005;112:332-40.

18. Ørbæk P, Kecklund G, Seger L, Åkerstedt T. Arbetsvecka på 84 timmar: trötthet, sömnmönster och stressreaktioner [84hour workweek: fatigue, sleep patterns and stress reactions]. Lund, Stockholm: Department of Occupational and Environmental Medicine, Lund University; National Institute for Psychosocial Medicine; 2000

19. Axelsson J, Ingre M, Åkerstedt T, Holmback U. Effects of acutely displaced sleep on testosterone. J Clin Endocrinol Metab. 2005;90:4530-5.

20. Campbell MJ, Julious SA, Altman DG. Estimating sample sizes for binary, ordered categorical, and continuous outcomes in two group comparisons. BMJ. 1995;311:1145-8.

Received for publication: 16 December 2005 